\title{
Editorial
}

\section{Thyroid FNA: Challenges and Opportunities}

\author{
Edmund S. Cibas ${ }^{\text {a }}$ Marluce Bibbo $^{\text {b }}$ \\ a Department of Pathology, Brigham and Women's Hospital, and Harvard Medical School, Boston, Mass., and \\ ${ }^{b}$ Department of Pathology, Jefferson Medical College, Philadelphia, Pa., USA
}

There was a shared sense of excitement and accomplishment among the participants at the conclusion of the 2-day National Cancer Institute (NCI) Thyroid FineNeedle Aspiration (FNA) State of the Science Conference in Bethesda, Md., USA, in 2007. Over 150 cytopathologists, surgical pathologists, endocrinologists, radiologists, and surgeons with an interest in thyroid disease had met for 2 days to talk about thyroid FNA, most notably about developing an evidence-based, common terminology for reporting thyroid FNA results. Since then, recommendations have been published, print and online atlases with definitions and criteria have appeared, and the resulting Bethesda terminology has been widely adopted in the USA and elsewhere. We are starting to speak the same language, at long last, and we look forward to reaping the benefits for patients and the healthcare system.

Where do we go from here? This issue of Acta Cytologica, with its focus on thyroid FNA, attempts to point the way. Although the terminology obstacle has been overcome, notable challenges remain, not the least of which is the application of the new terminology in practice. Ohori and Schoedel [1] lead off this issue with a review of the 6 categories of The Bethesda System for Reporting Thyroid Cytopathology (TBSRTC), with special attention to the category Atypia of Undetermined Sig- nificance or Follicular Lesion of Undetermined Significance (AUS/FLUS). The authors succinctly summarize the areas of diagnostic overlap between AUS/FLUS and other categories and suggest ways to avoid overusing AUS/FLUS.

Lobo et al. [2] present data from the UK on the histologic outcomes of the diagnostic categories for thyroid FNA that are used in the UK. Of note, the Royal College of Pathologists revised their thyroid FNA terminology in 2009 to allow for concordance between the UK system and TBSRTC. They found that the categories of the revised UK classification have clear and predictable risks of malignancy which permit management decisions based on the FNA interpretation.

Cochand-Priollet et al. [3] discuss the merits and challenges inherent in implementing TBSRTC in the European community at large. As part of this large endeavor, they share with the reader their reproducibility study, which included 4 participants representing several different European nations.

The following three papers dig deeper into the AUS/ FLUS category. VanderLaan et al. [4] examine variables that affect the AUS/FLUS rates of individuals, with an eye towards reducing overuse by providing confidential periodic feedback to pathologists on their AUS/FLUS rate. The authors report, among other things, that the AUS/

\section{KARGER}

Fax +4161306 1234

E-Mail karger@karger.ch

www.karger.com
(C) 2011 S. Karger AG, Basel

0001-5547/11/0556-0489\$38.00/0

Accessible online at:

www.karger.com/acy
Correspondence to: Dr. Edmund S. Cibas

Department of Pathology, Brigham and Women's Hospital

75 Francis Street

Boston, MA 02115 (USA)

Tel. +1 617732 6797, E-Mail ecibas@ partners.org 
FLUS rate of individual pathologists is inversely correlated with malignancy risk. Olson et al. [5] look at two major subcategories of AUS/FLUS - nuclear versus architectural atypia - and find a different association with histologic outcome. Luu et al. [6] find that cases called 'atypical follicular cells, cannot exclude papillary carcinoma' in their laboratories had a higher rate of malignancy than other subcategories of atypia. Their terminology predated TBSRTC, so the applicability of their results to current practice is unclear. Nevertheless, the results reinforce a point made by Ohori and Schoedel [1], namely that there is overlap between AUS/FLUS and the suspicious for malignancy category. Data like those presented here by Olson et al. [5] and Luu et al. [6] will help in establishing the ideal threshold for this distinction.

The study by Ono et al. [7] is an enlightening cytologic-histologic correlation for a distinct histologic subset of papillary thyroid carcinomas - those that arise within a follicular adenoma (abbreviated by the authors PTCFA). Not surprisingly, PTCFAs have subtle cytologic features; as a result, thyroid FNAs from these tumors are rarely interpreted as 'malignant'. The most common preceding cytologic interpretation is AUS/FLUS, and some thyroid FNAs from these tumors are even interpreted as 'benign', underscoring the limitations of cytology for some rare variants of papillary thyroid carcinoma.

The management of the patient with a repeatedly nondiagnostic thyroid FNA result remains a challenge. According to the American Thyroid Association, partially cystic nodules that repeatedly yield nondiagnostic aspirates need close observation or surgical excision, and surgery is more strongly considered if the cytologically nondiagnostic nodule is solid [8]. As implied by this carefully worded recommendation, the decision to perform surgery can be problematic. Prior studies have reported conflicting results with respect to the malignancy risk of repeatedly nondiagnostic aspirates. Jo et al. [9] contribute useful additional data and a thoughtful discussion, finding that there is no significant drop in the risk of malignancy with each successive nondiagnostic result.

Singh and Wang [10] critically examine the common approach of waiting a few months before repeating an aspirate in patients whose prior thyroid FNA was inconclusive. (The common recommendation is to repeat in 3-6 months). The rationale for waiting 3 months is based on the unproven concern that the interpretation of an aspiration obtained after a shorter interval might be confounded by an exuberant repair reaction. Contrary to expectations, Singh and Wang [10] find no difference in false-positive interpretations between early and late repeats. For the anxious patient who would like a more rapid repeat for a prior nondiagnostic or AUS/FLUS interpretation, this is welcome news. Of note, Jeronimo et al. [11] found a similar result for cervical cytology when they examined the ALTS trial database: namely that a short Pap interval (15-120 days) does not significantly affect the quality of liquid-based repeat cytology.

Mucin-producing tumors of the thyroid are rare and thus prone to misinterpretation due to one's unfamiliarity with them. Yang et al. [12] help correct this by describing the cytomorphology of three unusual tumors: a signet-ring cell follicular adenoma, a signet-ring cell variant of the follicular variant of papillary carcinoma (a variant of a variant!), and a mucinous poorly differentiated thyroid carcinoma.

The next group of papers highlights the interface between cytology and molecular diagnostics. Chang et al. [13] investigate five families with heritable forms of medullary thy roid carcinoma and find a strong correlation between the cytomorphology and the RET protooncogene mutation found within any given family. Colanta et al. [14] examine the utility of BRAF mutation analysis as an adjunct to cytology for thyroid FNAs; they find that it contributes little to reducing equivocal cytomorphologic findings since none of their AUS/ FLUS cases and only 3 of 17 suspicious for malignancy cases were positive for a $B R A F$ mutation. Different results are obtained by Adeniran et al. [15], who find a substantial frequency of $B R A F$ mutation in the subset of cases interpreted in their laboratory as indeterminate'. The difference in results between Colanta et al. [14] and Adeniran et al. [15] may be explained in part by differences in assay sensitivity and/or the diagnostic threshold separating AUS/FLUS from suspicious for malignancy. Smith et al. [16] report improved detection of $B R A F$ mutations in thyroid FNA specimens using an allele-specific/blocking probe polymerase chain reaction method.

Finally, Jordan et al. [17] present the results of a study examining the applicability of high-resolution magic angle spinning proton magnetic resonance spectroscopy as an adjunct to cytology to improve the detection of papillary thyroid carcinoma. Although the study size is small, the results are promising and point to a potential new direction for ancillary testing.

Our common terminology - TBSRTC - is still relatively new. As a result, many retrospective studies hitherto have had to retrofit the new terminology to cases originally interpreted using a different classification sys- 
tem and even, in some cases, different cytologic criteria. Nevertheless, with the proper caveats in mind, important insights can be gleaned from such studies. The opportunity for even more robust studies, either retrospective or prospective, and especially for collaboration among different laboratories now speaking a common language, is immense. We look forward to the fruits of the studies published here as well as future investigations into the benefits of cytology for the patient with a thyroid nodule.

\section{References}

1 Ohori NP, Schoedel KE: Variability in the atypia of undetermined significance/follicular lesion of undetermined significance diagnosis in the Bethesda System for Reporting Thyroid Cytopathology: sources and recommendations. Acta Cytol 2011;55:492-498.

2 Lobo C, McQueen A, Beale T, Kocjan G: The UK Royal College of Pathologists thyroid fine-needle aspiration diagnostic classification is a robust tool for clinical management of abnormal thyroid nodules. Acta Cytol 2011;55:499-506.

-3 Cochand-Priollet B, Schmitt F, Toetsch M, Vielh P, European Federation of Cytology Societies' Scientific Committee: The Bethesda terminology for reporting thyroid cytopathology: from theory to practice in Europe. Acta Cytol 2011;55:507-511.

4 VanderLaan PA, Krane JF, Cibas ES: The frequency of 'atypia of undetermined significance' interpretations for thyroid fineneedle aspirations is negatively correlated with histologically proven malignant outcome. Acta Cytol 2011;55:512-517.

5 Olson MT, Clark DP, Erozan YS, Ali SZ: Spectrum of risk for malignancy in subcategories of 'atypia of undetermined significance'. Acta Cytol 2011;55:518-525.
6 Luu MH, Fischer AH, Stockl TJ, Pisharodi L, Owens CL: Atypical follicular cells with equivocal features of papillary thyroid carcinoma is not a low-risk cytologic diagnosis. Acta Cytol 2011;55:526-530.

7 Ono JC, Wilbur DC, Lee H, Yang J, Krane JF, Bongiovanni M, Faquin WC: Cytologic features of focal papillary thyroid carcinoma arising within follicular adenoma: a masked cytomorphologic analysis of 17 cases. Acta Cytol 2011;55:531-538.

8 Cooper DS, Dohert GM, Haugen BR, Kloos RT, Lee SL, et al: Revised American Thyroid Association management guidelines for patients with thyroid nodules and differentiated thyroid cancer. Thyroid 2009;19:1174.

-9 Jo VY, VanderLaan PA, Marqusee E, Krane JF: Repeatedly nondiagnostic thyroid fineneedle aspirations do not modify malignancy risk. Acta Cytol 2011;55:539-543.

10 Singh RS, Wang HH: Timing of repeat thyroid fine-needle aspiration in the management of thyroid nodules. Acta Cytol 2011; 55:544-548.

-11 Jeronimo J, Khan MJ, Schiffman M, Solomon D, ALTS Group: Does the interval between Papanicolaou tests influence the quality of cytology? Cancer 2005;105:133-138.

12 Yang GCH, Scognamiglio T, Kuhel WI: Fineneedle aspiration of mucin-producing thyroid tumors. Acta Cytol 2011;55:549-555.
13 Chang IS, Chang CF, Yang WS, Chang TC: The relationship of cytomorphology of medullary thyroid carcinomas between family members with the same RET proto-oncogene mutation. Acta Cytol 2011;55:556-562.

14 Colanta A, Lin O, Tafe L, Ghossein R, Nafa K, Mitchell T, Ladanyi M, Arcila M: BRAF mutation analysis of fine-needle aspiration biopsies of papillary thyroid carcinoma: impact on diagnosis and prognosis. Acta Cytol 2011;55:563-569.

- 15 Adeniran AJ, Hui P, Chhieng DC, Prasad ML, Schofield K, Theoharis C: BRAF mutation testing of thyroid fine-needle aspiration specimens enhances predictability of malignancy in thyroid follicular lesions of undetermined significance. Acta Cytol 2011; 55:570-575.

16 Smith GD, Zhou L, Rowe LR, Jarboe EA, Collins BT, Bentz JS, Wittwer CT, Chadwick BE: Allele-specific PCR with competitive probe blocking for sensitive and specific detection of $B R A F \mathrm{~V} 600 \mathrm{E}$ in thyroid fine-needle aspiration specimens. Acta Cytol 2011;55:576583.

17 Jordan KW, Adkins CB, Cheng LL, Faquin WC: Application of magnetic-resonancespectroscopy-based metabolomics to the fine-needle aspiration diagnosis of papillary thyroid carcinoma. Acta Cytol 2011;55:584589. 